\title{
The WISDOM study: a new approach to screening can and should be tested
}

\author{
Laura Esserman ${ }^{1}$ (i) $\cdot$ Martin Eklund ${ }^{7} \cdot$ Laura van't Veer $^{1} \cdot$ Yiwey Shieh $^{1} \cdot$ Jeffrey Tice $^{1} \cdot$ Elad Ziv $^{1} \cdot$ Amie Blanco $^{1}$. \\ Celia Kaplan ${ }^{1}$. Robert Hiatt ${ }^{1}$ - Allison Stover Fiscalini ${ }^{1}$. Christina Yau ${ }^{1}$ - Maren Scheuner ${ }^{1}$ - Arash Naeim ${ }^{5}$. \\ Neil Wenger ${ }^{5}$. Vivian Lee ${ }^{1}$. Diane Heditsian ${ }^{1}$. Susie Brain ${ }^{1}$. Barbara A. Parker ${ }^{2}$. Andrea Z. LaCroix ${ }^{2}$. \\ Lisa Madlensky ${ }^{2} \cdot$ Michael Hogarth $^{2} \cdot$ Alexander Borowsky $^{3} \cdot$ Hoda Anton-Culver ${ }^{4}$ Andrea Kaster ${ }^{6}$. \\ Olufunmilayo I. Olopade ${ }^{8} \cdot$ Deepa Sheth $^{8} \cdot$ Augustin Garcia $^{9} \cdot$ Rachael Lancaster $^{10} \cdot$ Michael Plaza $^{11}$
}

Received: 8 June 2021 / Accepted: 28 July 2021 / Published online: 16 September 2021

(c) The Author(s), under exclusive licence to Springer Science+Business Media, LLC, part of Springer Nature 2021

In the recent opinion piece by Dr. Kopans, he takes exception to the WISDOM (Women Informed to Screen Depending on Measures of Risk) study, the on-going pragmatic trial of personalized screening vs. annual screening funded by the Patient Centered Outcomes Research institute (PCORI) and the National Cancer Institute (NCI). The personalized screening approach being investigated by WISDOM recommends a screening age to start and frequency based upon an individual breast cancer risk assessment $[1,2]$. There are two co-primary endpoints-one is safety, which is the rate

This editorial is a response to the review article https://link.springer. com/article/10.1007/s10549-017-4302-9

Laura Esserman
laura.esserman@ucsf.edu
Martin Eklund
martin.eklund@ki.se
Laura van’t Veer
laura.vantveer@ucsf.edu
Yiwey Shieh
Yiwey.Shieh@ucsf.edu
Jeffrey Tice
jeff.tice@ucsf.edu
Elad Ziv
elad.ziv@ucsf.edu
Amie Blanco
amie.blanco@ucsf.edu
Celia Kaplan
celia.kaplan@ucsf.edu
Robert Hiatt
Robert.Hiatt@ucsf.edu
Allison Stover Fiscalini
allison.stoverfiscalini@ucsf.edu

of Stage 2B or higher stage cancers (non-inferiority) and the other is morbidity, in terms of the rates of recall and breast biopsies (superiority). Secondary endpoints include preference, and uptake of prevention interventions [3]. PCORI challenged all grantees to identify early endpoints to improve the time it takes to learn from clinical trials. In other trials, we have also championed the use of early endpoints to accelerate knowledge turns, effectively using the neoadjuvant setting to evaluate new drug combinations in high-risk early stage breast cancer [4-6]. This approach has

Christina Yau

Hoisze.Yau@ucsf.edu

Maren Scheuner

Maren.Scheuner@va.gov

Arash Naeim

anaeim@mednet.ucla.edu

Neil Wenger

nwenger@mednet.ucla.edu

Vivian Lee

vlee@ aquapartners.net

Diane Heditsian

diane@declarity.com

Susie Brain

Susie_brain@yahoo.com

Barbara A. Parker

baparker@health.ucsd.edu

Andrea Z. LaCroix

alacroix@ health.ucsd.edu

Lisa Madlensky

lmadlensky@health.ucsd.edu

Michael Hogarth

mihogarth@health.ucsd.edu

Alexander Borowsky

adborowsky@ucdavis.edu 
now been widely adopted and even further has facilitated post-neoadjuvant therapy trials that have improved outcomes and led to significant advances in treatment and understanding of tumor biology. Modern treatment results in excellent 5- and 10-year outcomes for women with stage 1 and $2 \mathrm{~A}$ tumors [7]. Stage 2B tumors have a distinctly worse outcome and therefore, any increase in the rate of stage $2 \mathrm{~B}$ cancers would indicate inferiority [7].

While many of the points raised in the article are simply inaccurate, the overall tone of the article seems to miss the point of conducting a modern era study. The aim of the WISDOM study is, in the spirit of scientific investigation, to generate new evidence with the hope that it can improve breast cancer screening and lead to greater uptake of risk reducing interventions in the highest risk women. While one might argue there is no room for improvement over annual screening of all women over 40, the truth is that, in America at least, it remains a contentious issue and we are far from reaching any kind of consensus. While many radiologists consider annual screening mammography starting at 40 to be the gold standard, many internists, as well as large healthcare delivery systems, such as Kaiser Permanente and primary care organizations follow the US Preventive Services Task Force (USPSTF) guidelines of screening every other year starting at 50. In addition to the conflicting recommendations from trusted providers $[8,9]$-often within the same institution-there are at least 7 different screening guidelines offered up to American women, all of which differ on the age to start and the frequency of screening. This happens in no other western nation. And no other country, based on the same evidence, recommends annual screening starting at age 40. The confusion among women of screening age is no illusion, and certainly we have not "manufactured this debate" as the author posits. However, such controversy is exactly why we should be coming together to conduct studies in an effort to find a better way forward. And in fact, the urgency to better inform the public about such a critical health issue is exactly why the WISDOM study was chosen by PCORI for its inaugural pragmatic trial awards.

Part of the issue is that the majority of the evidence we do have comes from decades-old trials that were not designed to answer the questions we are asking today. There has been endless debate about statistical power for women aged $40-49$, and use of data from trials where mammography was analog or used single rather than 2 view imaging. Most importantly, these trials were conducted at a time when we thought all breast cancers were the same and that all women had an equal chance of developing a cancer.

But while we reanalyze, revise, and rehash the same old data, over 40000 women a year are still dying of breast cancer in the USA-despite screening. Women who present with stage 2 and 3 cancers today are most likely to have "interval cancers" and not found with screening, [10] there is disparity in who is most likely to die, we overtreat in situ disease, and $35 \%$ of women do not come in for screening at all. Does this not leave ample room for improvement?

This debate is reminiscent of the outcry over the trials testing mastectomy vs. breast conservation. Clinicians thought that doing less would increase mortality. But science prevailed, and the trials-strongly supported by womenwere conducted. What we have learned in the past three decades, over and over again, is that more is not necessarily better. More is just more. And sometimes more is worse. On the other hand, we have also learned that tailoring treatment to risk has led to significant improvements in outcomes and quality of life for women with breast cancer. The scientific method says that we must put these new ideas, and the old ones to the test, not settle for the status quo, and work across disciplines to make sure that our care tomorrow is better than it is today.

The premise of the WISDOM study is that, since all breast cancers are not the same, and not all women have the

\author{
Hoda Anton-Culver \\ hantoncu@uci.edu \\ Andrea Kaster \\ Andrea.Kaster@SanfordHealth.org \\ Olufunmilayo I. Olopade \\ folopade@medicine.bsd.uchicago.edu \\ Deepa Sheth \\ dsheth@ radiology.bsd.uchicago.edu \\ Augustin Garcia \\ agarc6@1suhsc.edu \\ Rachael Lancaster \\ rlancaster@uabmc.edu \\ Michael Plaza \\ mplaza@femwell.com
}

\footnotetext{
University of California, San Francisco, CA 94158, USA

2 University of California, San Diego, CA 92103, USA

3 University of California, Davis, Sacramento, CA 95817, USA

4 University of California, Irvine, CA 92868, USA

5 University of California, Los Angeles, CA 90095, USA

6 Sanford Health, Sioux Falls, SD 57104, USA

7 Karolinska Institutet, Stockholm, Sweden

8 University of Chicago, Chicago, IL 60637, USA

9 Louisiana State University, New Orleans, LA 70112, USA

10 University of Alabama, Birmingham, AL 35294, USA

11 Diagnostic Center for Women, Miami, FL 33173, USA
} 
same risk, there is an opportunity to improve our approach to screening using a precision medicine approach [1]. We have clearly defined the importance, rationale, and underlying evidence of each risk factor and how we are integrating these factors to determine screening intervals ahead of time. All of the screening recommendations in WISDOM fall within one or more of published US breast cancer screening guidelines $[1,11]$. These guidelines constitute a standard of care. We need to improve care and provide it in a more personalized manner that modern science now makes possible. Some may choose to believe that the status quo is good enough and that we cannot do better. We, the investigators and advocates that worked hard to develop this trial, and the 35000 women who have so far joined WISDOM do not agree.

\section{WISDOM has received multiple ethical approvals}

The trial design is the result of a multistakeholder process, described in Esserman et al. [1] that involved patient advocates, policy makers, guideline organizations, healthcare payers and physicians and scientists crossing multiple specialities. We solicited feedback from policy makers and guideline developers, including the National Committee for Quality Assurance (which issues the HEDIS measures).

The WISDOM study has been vetted and has received substantial peer reviewed funding from a number of federal agencies. The Patient Centered Outcomes Research Institute awarded one of its first pragmatic trial awards to start this study. As well, it has passed review from the National Cancer Institute and awarded a R-01 to improve diversity of women enrolling in the study. We are also working to further refine the risk models and trial outputs, to continue to build on lessons learned and the biology of breast cancer and advance the science of precision prevention.

Furthermore, WISDOM is, as all human trials are, subject to human subjects protection regulations. As such, the WISDOM protocol, including its risk stratification and screening recommendations, have received approval from Institutional Review Boards of ten different academic institutions. WISDOM is also overseen by an independent Data and Safety Monitoring Board that meets regularly to review study progress and safety.

A critical element of the risk-based approach is the genetic testing, which is not covered by the PCORI funding, nor is it covered by payers, as it is experimental. We were able to demonstrate, through modeling, that risk-based screening was likely to be cost-neutral and could potentially reduce harms of screening while improving healthcare value. These models allowed us to work with payers to obtain coverage for the genetic testing component (a relatively small portion of the overall costs) from multiple private and public
payers-Blue Cross Blue Shield, UC Care, CalPERS, Inland Empire (Medicaid), and a number of self-insured companies. Payer participation in WISDOM fosters the development of evidence, using a coverage with trial participation approach [12], all of which has been described in the WISDOM paper that Dr. Kopans cited. The study is investigator-led, by people who have devoted their professional lives to treating women with breast cancer, with the clear intention to test a model that has the potential to improve outcomes. The payers are taking a forward looking approach that will further the generation of evidence to help create better policy. They have absolutely no role in the analysis of the data or interpretation of the results. This helps us to advance the field and make trials more accessible to women across race, ethnicity, and socioeconomic strata. Further, it can reduce the time to implementing a change should the data warrant it.

\section{The WISDOM Study is a Pragmatic TRIAL}

The author's protracted concerns about the trial design and statistical analysis plans are addressed in the publication by Eklund et al. on WISDOM's analytic framework [3]. WISDOM has clearly documented that it is powered as a non-inferiority trial. The goal is to show that its risk-based approach is as safe and less morbid compared to annual screening, based on the endpoints of rate of diagnosis of stage IIB cancers or higher and the rates of recall and breast biopsies, respectively. As well, we are assessing rates of prevention uptake in the personalized vs. annual groups. Importantly, we are also incorporating anatomic and prognostic staging based on the AJCC 8 staging criteria, as we now understand that biology as well as anatomic stage are equally important in predicting outcome, and directing treatment. For both anatomic and prognostic staging, the difference in outcome for stage $1 \mathrm{~A}$ and $1 \mathrm{~B}$ and $2 \mathrm{~A}$ tumors is small, but there is a substantial increase in recurrence rates for stage 2B cancers, evident as early as 5 years [7].

WISDOM includes both a randomized cohort and an observational cohort. We adopted this preference-tolerant design at the urging of our panel of experienced patient advocates, as it allows all women to participate, even if they are unwilling to be randomized based on a strong personal preference. WISDOM's statistical analysis plan clearly dictates that the randomized cohort only will be used for the primary comparisons [3]. The preference-tolerant design is not unique to WISDOM and has been used successfully in many other trials, e.g., the SPORT trial [13-17]. One of the advantages of including an observational cohort is that it allows us to address a number of secondary questions, such as decisional regret and other patient-centered outcomes. With respect to the author's conclusion that "The ethics of 
this approach should be reviewed", we can only repeat that it has, multiple times-by PCORI, by NCI, by IRBs, by our international DSMB, by our External Advisory Board, by our patient advocates, and by our committed team of clinician-scientists.

As for tomosynthesis, we do not restrict or specify 2D or 3D mammography. The major study testing this (T-MIST) is being conducted now with a plan to report out in 2030 [18]. However, in advance of those results, the technology has largely been adopted and that will be reflected in our results.

It is also important to note that our current screening guidelines and risk models are biased against non-white women. Essentially all of our knowledge about the impact of screening, risk modeling, and opportunities for prevention has been generated from populations consisting largely of white women. WISDOM has received an R-01 from the National Cancer Institute to help us diversify the study population to ensure that it more closely reflects the makeup of the USA. If WISDOM is able to provide insight into risk and screening outcomes among non-white women that would also be an important contribution.

\section{The Debate}

Although the author makes the surprising claim that the debate over breast cancer screening "has been manufactured and is not science-based", the published record of the decades-long debate over screening should speak for itself, as should the author's enthusiastic participation in this debate, some of which has occurred in BCRT [19-21].

The question of whether there is overdiagnosis or overtreatment is semantic, but it is undeniable that screening finds more small low-risk biology lesions [22-24]. There is a wealth of peer-reviewed research describing overdiagnosis in breast cancer screening, which can be confirmed with a simple literature search. Even the most conservative estimates have placed overdiagnosis at $10 \%$. Where there is indeed scientific debate, is centered around what fraction of screen-detected cancers represent overdiagnosis. There are ongoing efforts to improve our diagnostic tools to identify ultralow risk tumors (those with minimal if any risk for metastasis) at the time of diagnosis, to reduce overtreatment [25]. In the treatment of breast cancer, we are increasingly targeting therapy with the intent to provide more effective treatment for those at highest risk of recurrence, and to de-escalate therapy in those with lowest risk [26, 27]. These changes are occurring in every discipline involved with breast cancer treatment. Our goal should be to improve the approach to screening and risk reduction, as well as diagnosis and treatment to improve outcomes and reduce morbidity-more (and more targeted) for those that need it, and less for those with lower risk. Indeed, this is the focus of the transition to precision medicine.

\section{Everyone in the WISDOM Study receives recommendations that fall within guidelines}

WISDOM in no way attempts to deny screening to any women-its investigators have never suggested this, nor would results from the study provide justification for doing so. In the cited WISDOM manuscript, it is clearly stated, "In the risk-based assessment arm, no woman will receive a recommendation for less screening than current USPSTF guidelines" [2]. In WISDOM, only those women in a low-risk category ( 5 -year absolute risk $<1.3 \%$ ) are recommended to begin screening at age $50[1,2]$. For women with $>1.3 \% 5$-year risk (approximate risk of the average 50-year-old), the recommendation is to begin screening at age 40 , with a frequency and modality commensurate to their risk.

WISDOM employs the Breast Cancer Surveillance Consortium (BCSC) model, which is validated in a population of over 1 million women across the USA. BCSC includes breast density as a risk factor. Importantly, we add genetic risk information-both the detection of inherited mutations (across 9 genes that predispose to a very high risk of breast cancer), as well as other inherited genes (single nucleotide polymorphisms) that together enable the calculation of a polygenic risk score (PRS). The addition of PRS to the BCSC model enables a better assessment of risk, and has been validated where the combined model explains $70 \%$ of breast cancer risk [28].

WISDOM does not propose screening 'only high-risk women'. Furthermore, there is clear evidence that riskbased screening can be effective. In fact, it is already a part of standard practice. Women who are at high risk, whether by genetic predisposition or other risk models, are already screened more intensively with breast MRI in addition to mammography - and a mortality benefit has indeed been demonstrated [29]. Women with dense breast tissue, a known risk factor, are often recommended to have supplemental screening. Even in the American College of Radiology Appropriateness Criteria for Breast Cancer Screening, the recommended frequency and modality of screening are stratified by risk [30]. In this regard, by evaluating routine risk assessment, WISDOM will help identify the very women who might benefit from more intense screening, and actually generate evidence about effectiveness of this approach.

Risk is also currently used as the basis for minimal or no screening in specific populations, based on genetics 
(Xy chromosomes) and age (women $<40$ years of age). Even though men and young women can develop breast cancer, screening is not routinely recommended for these populations because their risk is so low. Based on World Health Organization principles, screening for populations only make sense if the disease is relatively common. And intensive surveillance (every 6 months, alternating MRI, and mammography) is recommended for women who harbor a germline mutation such as BRCA 1 or 2 . With that in mind, it is hard to understand the resistance to investigating additional refinements to the concept of risk-based screening.

In fact, WISDOM is not alone in its effort to evaluate risk-based screening for breast cancer. There are efforts across the world to address the opportunity to personalize screening on the basis of risk, including the European MyPeBS study [31] and the Canadian PERSPECTIVE study [32]. A recent international conference resulted in a publication calling for support for trials using a risk-based approach, and to renew efforts to improve our approach to risk reduction in concert with screening [33].

It is important to underscore that risk-based screening is not an argument against screening mammography. On the contrary, it recognizes that screening is an important aspect of reducing breast cancer mortality, while simply acknowledging that there is room for improvement. This is WISDOM's goal, to determine if a risk-based approach can refine and improve screening in ways that preserve its ability to save lives, while reducing its potential harms.

Elias Zerhouni-radiologist-turned NIH directoradmonished in his 2007 Eugene P. Pendergrass New Horizons Lecture that "the greatest risk in science is to stop taking risks. For medical discovery and innovation to thrive in the future, we need to foster a culture that prizes habits of thinking outside the box, posing novel questions, and taking risks. Caution and safety are important but so too are courage and imagination. If our understanding is ever to reach a higher level, we must be willing to let go of the rung to which we are clinging [34]".

Dr. Zerhouni's words represent our philosophy about the WISDOM study. Our goal is to test new approaches for women that reflect the advances in risk assessment and treatment for breast cancer. The many regulatory bodies who have reviewed the WISDOM study have determined that the framework we have put forward in our clinical study is safe, and we are testing it to be sure. However, it is important to note that we are not offering a technology with an incremental benefit. We are testing a step change and a new direction; the advantages could be immense, because it would provide a platform upon which we can greatly amplify our efforts in surveillance and risk reduction for those at risk for the most lethal cancers, without incurring harm to those whose risk is low. We encourage all women to join with us and help support research toward a better future (wisdomstudy.org).

\section{References}

1. Shieh Y, Eklund M, Madlensky L et al (2017) Breast cancer screening in the precision medicine era: risk-based screening in a population-based trial. J National Cancer Inst 109(5):djw290. https://doi.org/10.1093/jnci/djw290

2. Esserman LJ (2017) The WISDOM Study: breaking the deadlock in the breast cancer screening debate. NPJ Breast Cancer 3(1):34 https://doi.org/10.1038/s41523-017-0035-5

3. Eklund M, Broglio K, Yau C, Connor JT, Fiscalini AS, Esserman LJ (2018) The WISDOM personalized breast cancer screening trial: simulation study to assess potential bias and analytic approaches. JNCI Cancer Spectr 2(4):279. https://doi.org/10.1093/ jncics/pky067

4. Consortium IST, Yee D, DeMichele AM et al (2020) Association of event-free and distant recurrence-free survival with individual-level pathologic complete response in neoadjuvant treatment of stages 2 and 3 breast cancer. JAMA Oncol 6(9):1355-1362. https://doi.org/10.1001/jamaoncol.2020.2535

5. Rugo HS, Olopade OI, DeMichele A et al (2016) Adaptive randomization of veliparib-carboplatin treatment in breast cancer. $\mathrm{N}$ Engl J Med 375(1):23-34. https://doi.org/10.1056/nejmoa1513 749

6. Nanda R, Liu MC, Yau C et al (2020) Effect of pembrolizumab plus neoadjuvant chemotherapy on pathologic complete response in women with early-stage breast cancer: an analysis of the ongoing phase 2 adaptively randomized I-SPY2 Trial. Jama Oncol 6(5):676-684. https://doi.org/10.1001/jamaoncol.2019.6650

7. Health CD of P. California Cancer Registry (2020). Accessed 26 May 2021. https://www.cdph.ca.gov/Programs/CCDPHP/DCDIC/ CDSRB/Pages/California-Cancer-Registry.aspx

8. Patel NS, Lee M, Marti JL (2021) Assessment of screening mammography recommendations by breast cancer centers in the US. Jama Intern Med 181(5):717-719. https://doi.org/10.1001/jamai nternmed.2021.0157

9. Habib AR, Grady D, Redberg RF (2021) Recommendations from breast cancer centers for frequent screening mammography in younger women may do more harm than good. Jama Intern Med 181(5):588-589. https://doi.org/10.1001/jamainternmed.2021. 0161

10. Lin C, Buxton MB, Moore D et al (2012) Locally advanced breast cancers are more likely to present as Interval Cancers: results from the I-SPY 1 TRIAL (CALGB 150007/150012, ACRIN 6657, InterSPORE Trial). Breast Cancer Res Treat 132(3):871-879. https://doi.org/10.1007/s10549-011-1670-4

11. Siu AL (2016) Screening for breast cancer: U.S. preventive services task force recommendation statement. Ann Intern Med 164(4):279. https://doi.org/10.7326/m15-2886

12. Rosenberg-Wohl S, Thygeson M, Fiscalini AS, et al (2017) Private payer participation in coverage with evidence development: a case study. Accessed 1AD. http://healthaffairs.org/blog/2017/03/ 14/private-payer-participation-in-coverage-with-evidence-devel opment-a-case-study/

13. Weinstein JN, Tosteson TD, Lurie JD et al (2006) Surgical vs nonoperative treatment for lumbar disk herniation: the spine patient outcomes research trial (SPORT): a randomized trial. JAMA 296(20):2441-2450. https://doi.org/10.1001/jama.296.20.2441

14. Weinstein JN, Lurie JD, Tosteson TD et al (2006) Surgical vs nonoperative treatment for lumbar disk herniation: the spine patient 
outcomes research trial (SPORT) observational cohort. JAMA 296(20):2451-2459. https://doi.org/10.1001/jama.296.20.2451

15. Weinstein JN, Lurie JD, Tosteson TD et al (2007) Surgical versus nonsurgical treatment for lumbar degenerative spondylolisthesis. New Engl J Medicine 356(22):2257-2270. https://doi.org/10. 1056/nejmoa070302

16. Weinstein JN, Tosteson TD, Lurie JD et al (2008) Surgical versus nonsurgical therapy for lumbar spinal stenosis. New Engl J Medicine 358(8):794-810. https://doi.org/10.1056/nejmoa0707 136

17. Wasmann KA, Wijsman P, van Dieren S, Bemelman W, Buskens C (2019) Partially randomised patient preference trials as an alternative design to randomised controlled trials: systematic review and meta-analyses. BMJ Open 9(10):e031151. https://doi.org/10. 1136/bmjopen-2019-031151

18. Lee C, McCaskill-Stevens W (2020) Tomosynthesis mammographic imaging screening trial (TMIST): an invitation and opportunity for the national medical association community to shape the future of precision screening for breast cancer. J Natl Med Assoc 112(6):613-618. https://doi.org/10.1016/j.jnma.2020.05.021

19. Kopans DB (2017) The Canadian National breast screening studies are compromised and their results are unreliable. They should not factor into decisions about breast cancer screening. Breast Cancer Res Tr 165(1):9-15. https://doi.org/10.1007/ s10549-017-4302-9

20. Narod SA (2017) Reply to kopans. Breast Cancer Res Tr 166(2):653-654. https://doi.org/10.1007/s10549-017-4465-4

21. Kopans DB (2017) Rebuttal comments. Breast Cancer Res Tr 166(2):655-656. https://doi.org/10.1007/s10549-017-4471-6

22. Drukker CA, Schmidt MK, Rutgers EJT et al (2014) Mammographic screening detects low-risk tumor biology breast cancers. Breast Cancer Res Tr 144(1):103-111. https://doi.org/10.1007/ s10549-013-2830-5

23. Esserman LJ, Shieh Y, Rutgers EJT et al (2011) Impact of mammographic screening on the detection of good and poor prognosis breast cancers. Breast Cancer Res Treat 130(3):725-734. https:// doi.org/10.1007/s10549-011-1748-z

24. Ernster VL, Barclay J, Kerlikowske K, Grady D, Henderson IC (1996) Incidence of and treatment for ductal carcinoma in situ of the breast. JAMA 275(12):913-918. https://doi.org/10.1001/jama. 1996.03530360023033
25. Esserman LJ, Yau C, Thompson CK et al (2017) Use of molecular tools to identify patients with indolent breast cancers with ultralow risk over 2 decades. JAMA Oncol 3(11):1503-1510. https://doi.org/10.1001/jamaoncol.2017.1261

26. Sparano JA, Gray RJ, Makower DF et al (2018) Adjuvant chemotherapy guided by a 21 -gene expression assay in breast cancer. $\mathrm{N}$ Engl J Med 379(2):111-121. https://doi.org/10.1056/nejmoa1804 710

27. Piccart M, van Veer LJ, Poncet C et al (2021) 70-gene signature as an aid for treatment decisions in early breast cancer: updated results of the phase 3 randomised MINDACT trial with an exploratory analysis by age. Lancet Oncol. https://doi.org/10. 1016/s1470-2045(21)00007-3

28. Vachon CM, Pankratz VS, Scott CG et al (2015) The contributions of breast density and common genetic variation to breast cancer risk. JNCI J National Cancer Inst. https://doi.org/10.1093/jnci/ dju397

29. Bae MS, Sung JS, Bernard-Davila B, Sutton EJ, Comstock CE, Morris EA (2020) Survival outcomes of screening with breast MRI in women at elevated risk of breast cancer. J Breast Imaging 2(1):29-35. https://doi.org/10.1093/jbi/wbz083

30. Mainiero MB, Lourenco A, Mahoney MC et al (2016) ACR appropriateness criteria breast cancer screening. Journal of the American College of Radiology : JACR 13(11S):R45-R49. https://doi. org/10.1016/j.jacr.2016.09.021

31. UNICANCER (2018) My personalized breast screening (myPeBS). https://clinicaltrials.gov/ct2/show/NCT03672331

32. Brooks JD, Nabi HH, Andrulis IL et al (2021) Personalized risk assessment for prevention and early detection of breast cancer: integration and implementation (PERSPECTIVE I\&I). J Personalized Medicine 11(6):511. https://doi.org/10.3390/jpm11060511

33. Pashayan N, Antoniou AC, Ivanus U et al (2020) Personalized early detection and prevention of breast cancer: ENVISION consensus statement. Nat Rev Clin Oncol 17(11):687-705. https:// doi.org/10.1038/s41571-020-0388-9

34. Zerhouni EA (2008) Major trends in the imaging sciences: 2007 Eugene P. Pendergrass New Horizons Lecture. Radiology 249(2):403-409. https://doi.org/10.1148/radiol.2492080481

Publisher's Note Springer Nature remains neutral with regard to jurisdictional claims in published maps and institutional affiliations. 